\title{
Supply chain semantic information modeling for data integration with BIM and FM
}

\section{Opinion}

Supply chain involves the flow of goods, services, money, and information to deliver a product. Construction supply chain must deliver the necessary material to project sites in correct quantity, with accepted quality, on time, and at the best price. Flow of information plays a major role in ensuring an efficient supply chain. Several organizations involved in a construction project such as owner, designer, general contractor, sub-contractors, manufacturers, material suppliers, transporters, and facility managers can benefit from sharing and easily exchanging information with each other. Each of these organizations acts based on the information they receive from other organizations; more accurate and up-to-date information results in more efficient supply chain system. Figure 1 shows a conceptual model of construction supply chain. A construction project uses multiple supply chains with different structures and behaviors. Usually, a supply company is involved in more than one construction project and should respond to demand information received from multiple projects. Also, a construction supply company might have to coordinate the upstream flow of materials within a supply chain. To coordinate supply chain and construction projects, information should flow between construction and supply chain companies in both ways. The problem is that data are stored in heterogeneous formats in different companies which make it difficult for computers to communicate and integrate data. Although Building Information Modeling (BIM) technologies have emerged to help the AEC-FM industry for information sharing, they still lack solutions to integrate the vast amount of supply chain data with BIM. BIM technologies

\author{
Volume 3 Issue 4 - 2017
} Mehrdad Niknam, Mohammad Hasan Sebt,
Abdollah Ardeshir

Department of Civil and Environmental Engineering,Amirkabir University of Technology, Iran

Correspondence: Mehrdad Niknam, Postdoctoral Researcher and Lecturer, Department of Civil and Environmental Engineering, Amirkabir University of Technology, Tehran Province, Tehran, District 6, $424 \mathrm{Hafez}$ Ave, Iran, Email mehrdad.niknam@gmail.com

Received: September 10, 2017| Published: October 13, 2017

enable the AEC-FM industry to have a shared virtual model of the project that includes both $3 \mathrm{D}$ geometry and information assigned as parameters to its elements. However, the information stored in BIM elements is not comprehensive and does not include supply chain data. For example, a product manufacturer catalog is more than 80 pages of data; the majority of which is not included in a BIM model. Although it is possible to attach the catalog to BIM elements (e.g. as pdf), attached documents cannot be easily queried by computers to find relevant data for different computing tasks in construction and facility management.

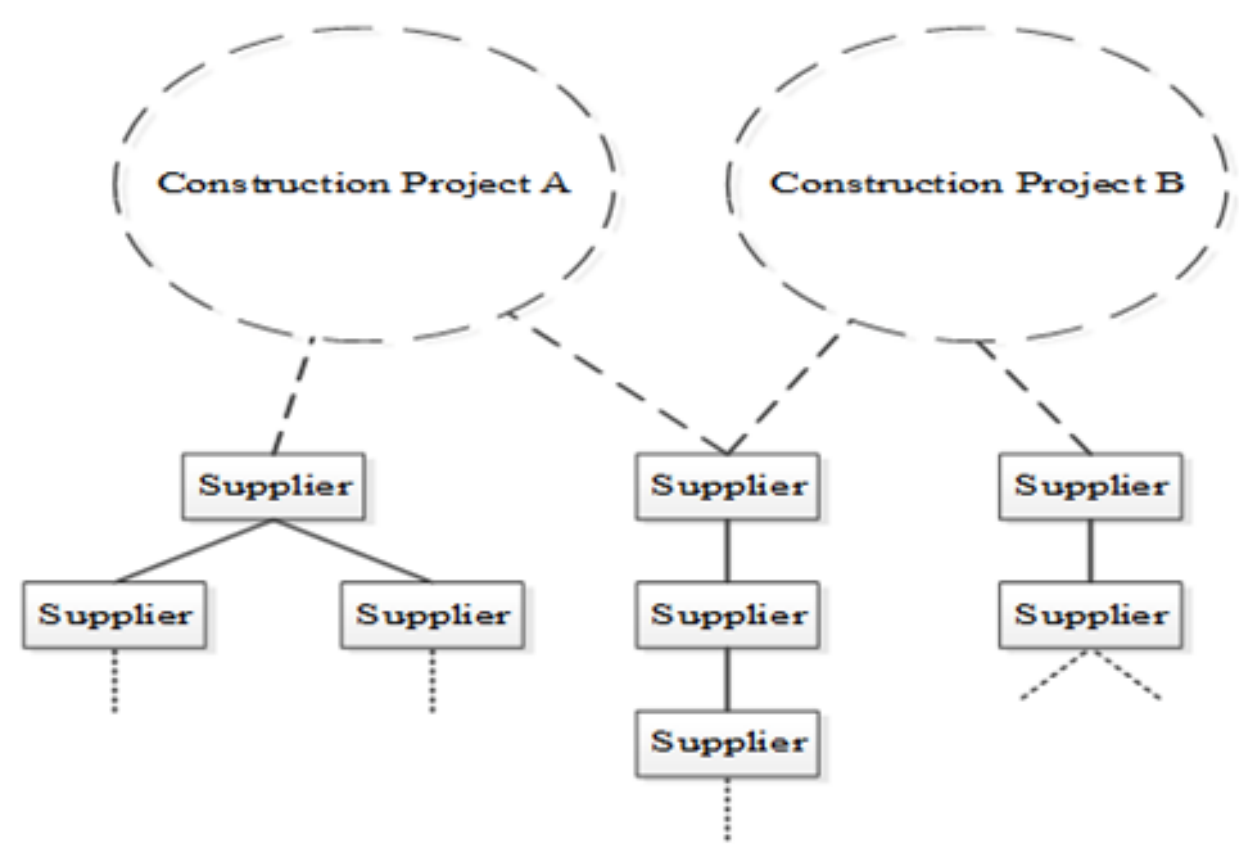

Figure I Conceptual model of construction supply chain. 
To solve this issue, data should be added to BIM elements in a structured way. However, manually inputting product supply chain data to BIM software is a very time consuming and error-prone task. Semantic Web Services, ${ }^{1}$ a component of Semantic Web ${ }^{2}$ technology, allows computer applications distributed over the internet to exchange semantically defined data. Semantic Web Services allow companies involved in construction supply chain to easily establish internet connections and exchange information. Each company needs to semantically define its web services and publish semantic descriptions of its web service on the web so that other companies' computer applications can communicate with it. A few studies have shown the applications of Semantic Web and Semantic Web services in AECFM projects. ${ }^{3-10}$. Figure 2 shows the communication system between a BIM knowledge base ${ }^{9}$ and a supplier's semantic web service that we have developed. A BIM knowledge base uses a semantic web service communication module to communicate with a supplier's semantic web service. The function of this module is to send product specifications (or product model number) to the supplier's web service and receive supplier's product information. This allows computers to integrate data instead of manual methods and saves a great amount of time as a result.

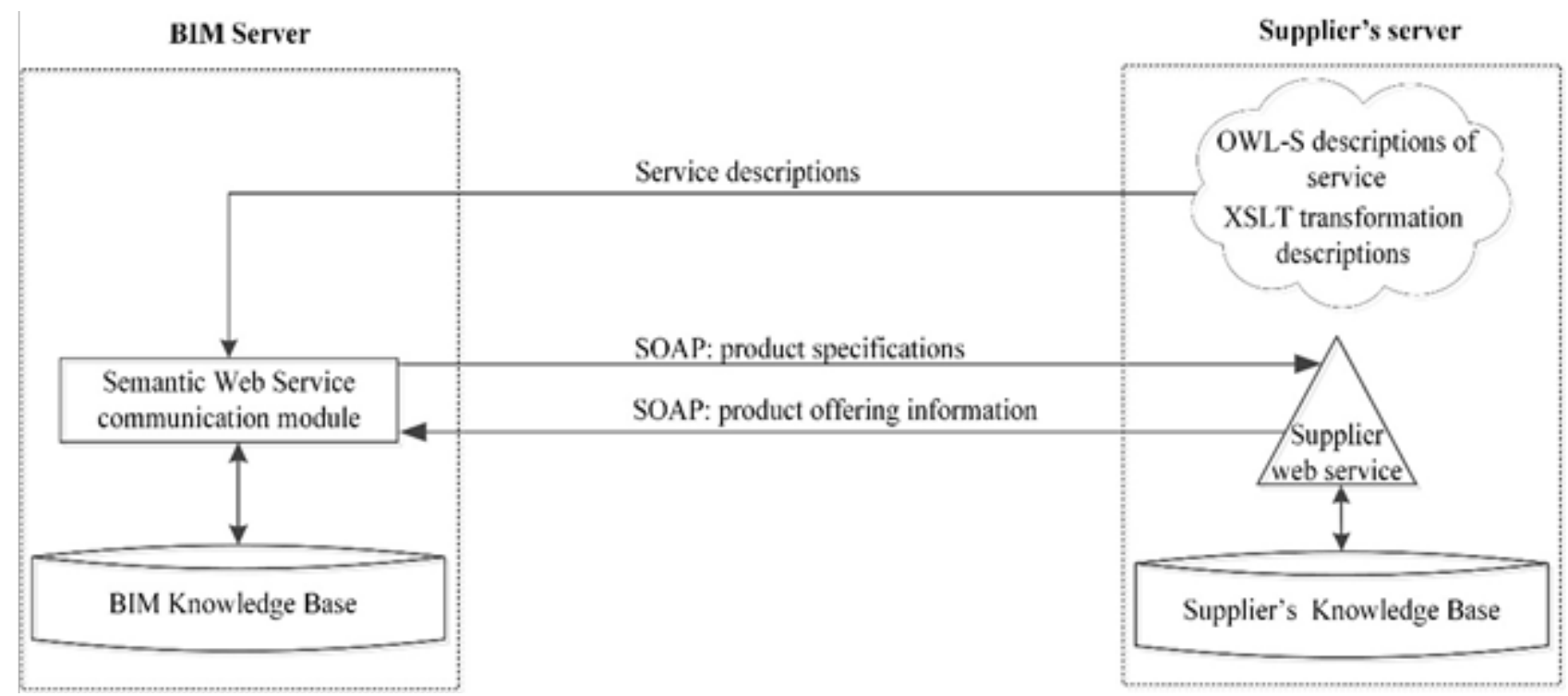

Figure 2 Integrating BIM and supplier data using semantic web services.

\section{Acknowledgments}

None.

\section{Conflicts of interest}

Authors declare there are not any actual or potential conflicts of interest.

\section{References}

1. OWL-S: Semantic Markup for Web Services. 2004.

2. Semantic Web. 2017.

3. Karshenas S, Niknam M. Ontology-based building information modeling. In Computing in Civil Engineering. 2013;476-483.

4. Niknam M. A semantics-based approach to construction cost estimating. USA. Marquette University; 2015.
5. Niknam M, Karshenas S. Integrating BIM and Project Schedule Information Using Semantic Web Technology. In Construction Research Congress; 2016.

6. Niknam M, Karshenas S. A semantic web service approach to construction cost estimating. In Computing in Civil Engineering. 2013:484-491.

7. Niknam M, Karshenas S. Sustainable design of buildings using semantic BIM and semantic web services. Procedia Engineering. 2015;118:909-917.

8. Niknam M, Karshenas S. A social networking website for AEC projects. In Computing in Civil and Building Engineering. 2014;2208-2215.

9. Niknam M, Karshenas S. A shared ontology approach to semantic representation of BIM data. Automation in Construction. 2017;80:22-36.

10. Niknam M, Karshenas S. Integrating distributed sources of information for construction cost estimating using Semantic Web and Semantic Web Service technologies. Automation in Construction. 2015;57:222-238. 